\title{
Educación y museos: el ejercicio de la mirada
}

\author{
María Antonieta Sibaja Hidalgo \\ Museo de Arte y Diseño Contemporáneo de Costa Rica
}

\begin{abstract}
Resumen
La educación del visitante a los museos tiene un componente más allá de lo puramente didáctico, el cual se relaciona con el conocimiento del arte como lenguaje y de la historia del arte. Así mismo, es importante establecer las fronteras con otros géneros que utilizan la imagen como el cine y el documental. Este es el propósito del artículo.
\end{abstract}

Palabras claves: educación, museos, videoarte, video-perfomance, video-instalación

\begin{abstract}
Education in museums exceedes the didactic purpose and is related to art language and history of art. It is also important to draw the borderland with other artistic expressions based on image like movie picture and documentary. This is the aim of the article.
\end{abstract}

\section{Keywords}

Education, museums, video-art, video-performance, video-instalation

$\mathbf{M}$ e propuse escribir un artículo sobre la educación en museos y curiosamente me encontré un texto del venezolano José Luis Blondet que se titula La mala educación en los museos. Conforme lo leía me sentía más identificada con lo que decía, desde su primera confesión donde menciona el haber estudiado en un centro de estudios curatoriales para dedicarse de lleno al trabajo curatorial y acepta una oferta para crear el departamento de educación de un nuevo museo en Beacon, Nueva York. Mi caso es similar, estudié historia del arte y no sabía que me ofrecerían la coordinación del departamento educativo en un museo.
Sin embargo, lo tomé como una gran oportunidad y me entregué por completo a la educación, aplicando el interés por los discursos de las obras de arte.

Blondet cuestiona que los departamentos educativos de los museos están formados por especialistas en educación, que despliegan herramientas metodológicas muy eficientes para fines didácticos, pero que no saben muy bien qué están enseñando. Coincido con él y considero es una gran responsabilidad mediar entre la obra y el espectador y ni qué decir cuando se trata de "educar" en relación con el arte contemporáneo, donde lo conceptual prima 
sobre la técnica. Aún más complejo si se trata de videoarte, video-instalación o video-performance, lenguajes artísticos que se acercan al uso de lo tecnológico del video y exploran formatos y tipologías en el área del audiovisual.

Estas imágenes en movimiento que encontramos en un museo, dentro del imaginario cultural de cada visitante, invitan a pensar sobre las fronteras que existen con otras categorías como cine, documental, videoclip y campañas comerciales. El punto de partida será entender la diferencia que existe entre ellos.

Las personas buscan en los videos, más que información, placer; en sociedades donde el uso de la tecnología es fundamental, con acceso a Internet se permite el flujo de información y entretenimiento en línea. El visitante que llega a un museo y encuentra una obra en formato audiovisual, podría sentirse identificado por un medio que le es familiar e indagar sobre un estímulo que va más allá del entretenimiento. Asimismo, podría sentir que el museo deja de ser un espacio que conserva objetos antiguos, a los que sabemos cómo enfrentarnos, y nos incita a explorar conceptualmente una obra que nos condiciona temporalmente al tener una duración.

\section{Abordajes de la mirada}

Partimos de la pregunta: ¿Vemos únicamente lo que sabemos? Para abordar este tema partimos de la pedagogía de la imagen, influenciados por los textos de Ana Abramowski, profesora e investigadora, magister en Ciencias Sociales con Mención en Educación. Ella señala cómo a pesar de que nuestros conocimientos configuran nuestras miradas, es posible ver más allá de nuestro saber, cuestionando así nuestros conocimientos y provocando, en algunos casos, desestabilizarlos. A la hora de trabajar con videoarte, video-instalación y video-performance en un museo, vamos a tomar en cuenta la existencia de la relación entre ver -sentir- pensar, en la medida en que las imágenes en movimiento se pueden vincular con emociones y conocimientos en distintas áreas, además de que podemos analizar y desarrollar conceptos o ideas sobre algo o alguien.

Para Nicholas Mirzoeff (2003), teórico y profesor del Departamento de Medios, Cultura y Comunicación de la Universidad de Nueva York, la inmediatez sensual es propia del mirar. Para Didi Huberman (1997), historiador de arte y ensayista francés, al mirar hay que abrir los ojos para experimentar lo que no vemos, la evidencia visible que no vemos y que nos mira como una obra. Ahora bien, ¿cómo se trabajaría en una intervención pedagógica a partir de la utilización del video? ¿Cómo empujar la mirada hacia los bordes? Para ello se tendría que explorar qué tipo de conocimientos podemos trabajar con los videos en relación con la mirada.

Para trabajar en la educación no formal con los lenguajes artísticos del videoarte, video-instalación y video-performance se debe prestar atención a cómo explotar el poder de los lenguajes con solo mirar y escuchar, la apertura a múltiples significados y la construcción de estos desde el ver y el saber. Cada vez que un espectador mira y escucha esos trabajos audiovisuales, construye nuevos significados; con esto se 
quiere recalcar la importancia de la participación del espectador y las posibilidades de lectura que se logran obtener.

Si buscamos trabajar pedagógicamente con estos lenguajes de arte contemporáneo, debemos valorar las posibilidades antes mencionadas y la riqueza de múltiples miradas e inclusive sensaciones que nos permiten tener. Además, debemos decir, que al lado de la pedagogía de la imagen en movimiento, siempre hay una subjetividad, la construcción de una mirada que detrás de sí carga una política.

Los programas educativos de los museos deben estar desarrollados a partir de pensamiento crítico, para construir tomando en cuenta la opinión de las otras personas. Por tanto, su aplicación comprende preguntas y construcciones grupales.

Debemos de tomar en cuenta algunos aspectos como que el aprendizaje comienza con los sentidos. Los sentidos reciben información del entorno y la transmiten al cerebro para ser procesada. Estimular la capacidad de conocer sobre arte a partir de los sentidos, ayudará a los visitantes del museo a desarrollar su imaginación, percepción y sensibilidad. En los museos actuales se busca crear experiencias en los visitantes, y es por medio de obras que podemos utilizar el sentido de la vista y el oído que más fácilmente se puede trabajar en ello.

Para desarrollar este aspecto se toma como ejemplo un video-performance del artista panameño Brooke Alfaro: Nueve en vivo TV (2003). La pieza consiste en dos proyecciones simultáneas de pandillas enemigas del Barrio de Barraza, ubicado en El Chorrillo, uno de los sectores más peligrosos de Ciudad de Panamá, y cantan las mismas canciones. Cada banda interpretó dos canciones del cantante panameño de "reggaetón" El Rookie, y el artista las colocó de manera sincronizada.

Con este ejemplo se puede resaltar otro aspecto importante de tomar en cuenta: se deben ofrecer medios contra el poder de la seducción o seducirlos con la interpretación crítica de las imágenes en movimiento. Al ver y escuchar las canciones, los espectadores se podrían sentir identificados con la música y ésta les podría transmitir un sentimiento. El ritmo pegajoso del "reggaetón" y la letra en relación con la violencia urbana permite hacer relaciones con las imágenes de los jóvenes pandilleros, cantando con el rostro lleno de ira. El departamento educativo debe decidir cuál de todas las posibilidades de lectura potencia con los diferentes grupos de personas.

El dinamismo de la imagen es otro factor que atrapa a los visitantes. Ver un video permite entender más fácilmente que el tema del que se habla puede suceder en la realidad. En este caso ponemos como ejemplo la visualización de un videoperformance de la artista guatemalteca Regina Galindo: ¿Quién puede borrar las huellas? (2003). El video consiste en ver a una mujer (la misma artista) que camina con un recipiente de sangre humana, con la que va mojando sus pies y deja sus huellas por la calle. ¿Es real que la artista camine dejando sus huellas con sangre? ¿Por qué razón lo hace? Esto da pie para hablar del contexto guatemalteco en que fue creada la pieza, los acontecimientos políticos de la época en que fue creada, que 
nos hablan de las razones por las cuales la artista decide realizar esta acción, como lo es la noticia de que el exmilitar Efraín Ríos Montt se lanzó a la candidatura presidencial. Podemos reconocer los espacios que recorre, que se convierten, en esta pieza, en lugares simbólicos; el recorrido desda la Corte de Constitucionalidad hasta el Palacio Nacional de Guatemala. ¿Qué significa la sangre en ese contexto y cómo cambia la lectura de la utilización de sangre en

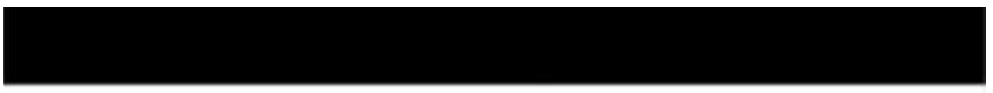
otra obra de otro artista? Este podría ser un abordaje de una obra con una postura política en relación con el conflicto armado en Guatemala.

Con este ejemplo nos acercamos a otros dos aspectos fundamentales: primero, debemos de conocer el contexto en el que fue creada la obra y la procedencia del artista, ya que muchas veces hay conexiones entre ambos. Segundo, las obras brindan información y pueden mostrar temáticas de importancia social.

También existen obras donde no es necesario conocer el contexto, podría decirse que poseen un lenguaje universal, es el caso de Usando a John (2005), videoarte de la artista costarricense-mexicana Paulina Velázquez. La obra consiste en una animación basada en una persona real, un amigo de la artista que aceptó ser "apropiado" para formar parte de otra realidad. Es una secuencia procesual simple de la

imagen lúdica de John, donde el audio forma parte importante de la pieza; no es una canción ni se habla ningún idioma, utiliza un canto de garganta.

Un factor que los departamentos educativos deben tomar en cuenta radica en analizar la relación de video-construcción-representación. Para ello tenemos el ejemplo de la video-instalación de la artista nicaragüense Patricia Belli: Equilibrista (2005), donde se juega con la representación y la realidad. La obra consiste en una proyección donde se observan sujetos entre nubes. Al moverse las nubes se produce un efecto donde los sujetos parece que se mueven también. En esta obra de una manera íntima y sutil se relacionan imagen detenida y en movimiento.

Otro elemento que los departamentos educativos pueden abordar consiste en que se debe formar a los visitantes como receptores críticos y sujetos activos. Para ello 
tenemos el ejemplo de la video-instalación del artista costarricense Joaquín Rodríguez del Paso: Saltamontes (2006), donde la misma pieza parte de preguntas. La instalación consiste en dos televisores colocados en el piso que se dan la espalda, rodeados de saltamontes hechos de hoja de palma. En uno de los videos se le pregunta a nicaragüenses que viven en Costa Rica: ¿quién es Juan Santamaría? (héroe de Costa Rica) y en el otro se le pregunta a costarricenses: ¿cuál es el héroe nacional de Nicaragua? Las respuestas de los entrevistados en los videos denotan un desconocimiento por el país limítrofe. Esta obra da pie para abordar el tema de la migración desde múltiples perspectivas y adentrarse en la historia de cada uno de los países y las relaciones políticas, económicas, sociales y culturales entre ellos.

\section{Otro factor por tomar en cuenta es que} el lugar donde se exponga la obra puede ser un elemento importante para potenciar la pieza. Tanto en el contexto costarricense como en el contexto nicaragüense, la obra Saltamontes se potencia, ya que las personas se pueden identificar con sus propias costumbres y referentes nacionales. Esto no quiere decir que su exposición no funcione en otros contextos.

Asimismo, se pretende enfatizar en el contenido de los videos. No nos podemos quedar en análisis simplistas de forma, cuando los museos deben de ser sujetos de cambio para la transformación de las sociedades con mira a la sostenibilidad. Esto se lograría con esfuerzos por interrogar la mirada, el acto de ver y el sujeto que mira.

Los departamentos educativos pueden insistir sobre la fuerza que posee la imagen en movimiento $\mathrm{y}$ desarrollar ejercicios donde se desarrolle el pensamiento crítico. Por ello, al trabajar con grupos de visitantes, ya sea con obras de videoarte, video-instalación, video-performance $u$ otros lenguajes artísticos, debemos preguntarnos lo siguiente: ¿Cómo se piensa la relación ver-saber? ¿Qué nos provoca el video y que códigos podemos interpretar de ellos mismos? ¿Cuál es la intención de los artistas y su contexto? Se puede abordar la obra audiovisual como vehículo de atracción, motivación e interés que permite habilitar aprendizajes. Los conocimientos sobre distintas disciplinas para quienes trabajan en educación en museos van a ser fundamentales para el abordaje de este tipo de obras por medio de actividades. Tenemos que saber, además de historia del arte, sobre literatura, semiótica, filosofía, sociología, entre muchas otras áreas. Además, estar informados sobre temas de actualidad nacional e internacional es muy útil y básico al trabajar con arte contemporáneo, ya que tanto las obras se construyen en la contemporaneidad como se pueden crear vínculos con obras realizadas en cualquier época y hacer lecturas a raíz de temas que están sucediendo.

Sin embargo, aunque una persona puede investigar constantemente y llegar a conocer distintas áreas, no es posible que logre ser un especialista en todo, para abarcar todas las temáticas presentes en las obras de arte y necesidades del área educativa. Además, los museos poseen límites en relación con presupuestos para optar por numerosos departamentos educativos con personas de distintas áreas. ¿Qué podemos hacer al respecto? En los proyectos generados en el museo donde me desempeño, 
solventamos estas necesidades con la creación de programas de voluntariado con personas de distintas disciplinas, que trabajan en proyectos específicos de acuerdo con su área en relación con las obras. Los voluntarios son un buen equipo de apoyo, pero tenemos que tener claro que son un apoyo y necesitan formación.

Entre las lecciones aprendidas, se encuentra que al trabajar con equipos interdisciplinarios se expone a la audiencia a experiencias que no habían sido vividas y exploradas previamente. Es por esta razón que desarrollamos proyectos específicos vinculados a las exposiciones y programas permanentes, desarrollados en fases donde invitamos a especialistas de distintas áreas para trabajar en dos modalidades. La primera consiste en invitar a artistas para impartir charlas, talleres y conferencias en la materia de interés, con libertad de diseñar todos los contenidos. La segunda modalidad consiste en invitar tanto a artistas como a personas de distintas áreas para trabajar con las obras desde distintas disciplinas. Por ejemplo, formar un en equipo con una persona del departamento educativo y músicos invitados, para trabajar con un videoarte sin sonido con un grupo de estudiantes. Para el departamento es importante brindar suficiente información sobre las obras y exposición en general a las personas colaboradoras de distintas áreas, para proponer en conjunto de actividades con objetivos bien planteados y relacionados directamente con las temáticas de las obras. Ellas deben hacer énfasis en el desarrollo de la criticidad de los participantes.

Todas estas actividades deben acompañarse de evaluaciones para los participantes y facilitadores, que tomen en cuenta aspectos espaciales relacionados con el entorno y cognitivos sobre la experiencia en el museo, además de aspectos técnicos vinculados con el aprendizaje de contenidos sobre las obras de arte y la opinión sobre la forma en que las actividades se llevaron a cabo. En la medida de lo posible, se pueden realizar guías de observación adecuadas a las características de los distintos grupos de participantes.

De esta manera, con la colaboración de distintos actores y una buena organización de las actividades, se pueden hacer abordajes integrales de las obras y crecer como departamento educativo.

Finalmente ¿Qué significa mirar? Podríamos referirnos a desarmar, develar, discernir, analizar más allá de simplemente emocionarse, perderse. Mirar es pensar en las múltiples posibilidades de trabajar en educación no formal, no hay límites para imaginar qué aportes podemos hacer para trabajar a partir del arte y de la plataforma del museo en la creación de sociedades críticas y sostenibles. Pensar sobre ello es importante para encontrar sentido en lo que vemos, establecer relaciones y cuestionar qué hay más allá de la imagen. Se busca en este artículo escudriñar las posibilidades de la mirada. 


\section{Bibliografía}

Abramowski, A. (s/f). El lenguaje de las imágenes y la escuela ¿Es posible enseñar y aprender a mirar? Recuperado de http://www.me.gov.ar/ monitor/nro13/dossier2.htm

Díaz Bringas, T. y Pérez Rattón, V. (eds.), Teor/ética (2008). Arte crítico y crisis del arte: Situaciones artísticas latinoamericanas II. Texto: La mala educación de los museos (p.82-88). San José.

Huberman, G. (1997). Lo Que Vemos, lo Que Nos Mira. Buenos Aires: Editorial Manantial.

Mirzoeff, N. (2003). Una introducción a la cultura visual. Barcelona: Paidós.

Moxey, K. (2009). Los estudios visuales y el giro icónico. Estudios Visuales, $n^{\circ} 6$ (p. 7-27). 